\section{References}

BARNES, T. R. E. (1990) Comment on the WHO consensus statement. British Journal of Psychiatry, 156, 413-414. BAZIRE, S. (1995) Psychotropic Drug Directory 1995, p. 42. Milton Keynes: Lundbeck.

Double. D. B., Warren, G. C., Evans, M., et al (1993) Efficacy of maintenance use of anticholinergic agents. Acta Psychiatrica Scandinavica, 88, 381-384.

JohNSTONE, E. C. Crow, T. J., Ferrier, N. I., et al (1983) Adverse effects of anticholinergic medication on positive schizophrenic symptoms. Psychological Medicine, 13. 513-527.

WORLD Health ORganization (1990) Prophylactic use of anticholinergics in patients on long-term neuroleptic treatment. A consensus statement. British Journal of Psychiatry, 156, 412.

Justin H. G. Williams, Specialist Registrar, Department of Psychiatry. University of Dundee, Ninewells Hospital and Medical School, Dundee DD1 9SY

\title{
Profile of staff grade psychiatrists
}

\author{
Aileen Blower
}

\begin{abstract}
Alms and method Staff grade psychiatrists working in Scotland were surveyed by postal questionnaire in order to determine their demographic profile, career aspirations and experience of the grade.

Results A heterogeneous group of doctors was identified, from a variety of professional backgrounds, and with a range of ambitions. Respondents generally held a favourable view of the grade, but expressed concern over percelved lack of opportunities for training, education and career progression. This is despite considerable recent efforts by the College to include non-consultant career grades in its programme for Continuing Professional Development.

Clinical implications There remains scope for imaginative development of the grade. In particular. staff grade psychiatrists might benefit from a more individualised approach to, and support for, all areas of their professional development. Such 'mentoring' may be especially beneficial for staff grades in Scotland, for whom geographical, as well as professional isolation, can be problematic.
\end{abstract}

The staff grade was introduced following the recommendation contained in the report Hospital Medical Staffing: Achieving a Balance (Department of Health and Social Security (DHSS), 1986). It was expected that doctors who were 'unable or unwilling' to become consultants would enter this grade from senior house officer level, attracted by the security and intermediate responsibility of the grade. Career advice for all junior trainees was also recommended by the report. To prevent the staff grade growing too rapidly at the expense of consultant appointments, manpower controls should ensure that the maximum number in the staff grade does not exceed $10 \%$ of the total number of consultants. Finally, in the consultation that followed, it was recognised that, although not a formal training grade, adequate and continuing education would be essential (DHSS, 1987).

Previous studies have surveyed staff grade doctors and dentists, across different specialities, within England and Wales (Standing Committee on Postgraduate Medical Education (SCOPME, 1994) and Scotland (Scottish Council for Postgraduate Medical and Dental Education (SCPME), 1996). Educational needs of staff grade psychiatrists within the South-East Thames region have also been examined (Stein, 1997). These reports have expressed concern regarding: lack of career advice; confusion over the status of the grade; need for continuing medical education; isolation in the grade; and exclusion from career progression. The larger studies also showed that the majority of staff grades in England and Wales were overseas qualified men, while, in Scotland, female UK qualifiers were over-represented.

This study focused on psychiatrists within Scotland, in order to determine if they share characteristics and views with their staff grade colleagues in all other specialities.

\section{The study}

In Spring 1997, a semi-structured questionnaire was posted to all doctors currently serving in a staff grade psychiatry post within Scotland. Staff grade colleagues assisted in compiling the 
database. Posts were identifled by contacting all hospital and National Health Service trust administrators within Scotland and asking them to supply doctors' names. As a means of estimating the comprehensiveness of this database, I compared the total number of staff grades in the study population with the number of consultant psychiatrists posts identified in Scotland by the College Census (Royal College of Psychiatrists, 1995), applying the aforementioned ' $10 \%$ rule'. Subjects were asked about their prior training and experience; reasons for applying for, and remaining in the post; working environment; educational activities and needs: career aims; and perceptions of the grade. Apart from where yes $/ \mathrm{no}^{\circ}$ responses were appropriate, subjects were invited to respond in 'free text'.

\section{Findings}

\section{Subjects}

Thirty-nine staff grade psychiatrists were identified in Scotland, of whom 29 (74\%) work within the West region. For comparison, the 1995 College Census identified a total number of 353 consultant posts within the whole of Scotland, and 142 in the West. Since this study sample represents $11 \%$ of the total number of consultants (and 20\% in the West area), our database is unlikely to seriously underestimate the true staff grade psychiatry population in Scotland. Replies were received from 25 doctors, so the response rate was $66 \%$.

By examining doctors' names in the database, I could assume that women represented $62 \%$ of the total number of Scottish staff grade psychiatrists. Females were over-represented in the study sample, since replies were received from 18 women (i.e. $72 \%$ of respondents). The sample was more representative of geographical area, since $76 \%$ of replies were received from staff grades in the West of Scotland. Most respondents were born and qualified in the United Kingdom (mainly Scotland). Three women and one man were born and qualified overseas. One man, born overseas, was qualified in Scotland.

The average age of respondents was 38 years. Men were generally older than women (average 42 and 37 years, respectively). Female respondents who qualified overseas were five years older on average than their UK qualified counterparts.

Respondents were generally well qualified, though not necessarily in psychiatry. The numbers of respondents possessing a particular postgraduate qualification were: MRCPsych five, MRCGP five, MRCP one, MFCM one, DRCOG three, DipMedEd one, PhD one, MPH one.

Considering existing links to the Royal College of Psychiatrists, four respondents were members, three were Affiliates and one an Inceptor.
Five respondents were approved under Section 20 of the Mental Health (Scotland) Act 1984. The average length of time spent in the current post was 2.2 years (range two months to eight years).

\section{Route to the staff grade}

The number of respondents occupying a particular grade directly prior to their current staff grade post were senior house officers (SHO) five, registrar 12, senior registrar (overseas equivalent) one, consultant (public health) one, general practitioner (GP) one, staff grade one, clinical assistant three. Fifty per cent of respondents were recruited to the grade directly from registrar level, and $25 \%$ had at least three years' experience as a SHO. Most of those individuals who were recruited directly from non-consultant career grades (clinical assistant or staff grade post) had previously been psychiatric registrars. Half of the respondents had received helpful career advice prior to applying for their current staff grade position, mainly from clinical tutors and other senior consultants.

\section{Reasons for entering, and remaining in, the grade}

All subjects offered more than one response to the open question Why did you apply for your current staff grade post'. The reasons given have been grouped into the following categories: working hours 14; intrinsic value of post, clinical experience 11 , training opportunities three, intermediate level of responsibility five; breaking from training 11; family/personal reasons nine; stability of post eight; route into psychiatry three. Overall, a variety of positive and negative reasons were offered. The most popular were regular 'office hours' with avoidance of 'on call' commitments, and the intrinsic educational/ experiential value of the post. Interestingly, several respondents regarded the post as a 'super training' opportunity, with, for example, more varied or unusual experience. In particular, subjects valued the increased opportunities, afforded by the stability of the post, to establish longer-term relationships with patients and colleagues. Some commented on enjoying becoming an established team member, compared with the more temporary experience of being a trainee. Others welcomed having more time to prepare for membership examinations, or participate in longer-term research/audit projects. Five respondents valued having an intermediate level of clinical/managerial responsibility and autonomy.

Domestic/family commitments and other personal reasons were mentioned in relation to favourable working conditions (such as regular hours), and the stability and flexibility of the 
post. Many described wishing a temporary or permanent break from formal training. The former involved regarding the grade as a convenient 'detour' from the conventional career ladder.

Three subjects had entered the staff grade as a convenient route into psychiatry, either from a career break, or from a different speciality.

Inability to progress in formal psychiatric training was also described, either due to expiry of a registrar post, exhaustion of opportunities to sit examinations, or perceived difficulty competing with other trainees due to age or cultural reasons.

All respondents chose to remain in the grade for these same original reasons, and many added further positive reasons based on their favourable experience of the grade, such as enjoying clinical work and educational opportunities, as well as general improvement in their personal well-being and quality of life.

\section{Working environment}

The principal workbase (four respondents had two main workbases) for the respondents were: community mental health team base 12 , psychiatric hospital nine, day hospital five, district general hospital two, rehabilitation unit one. Scottish staff grades mostly practice within adult general psychiatry, although sub-specialities of old age and child/adolescent psychiatry, and learning disability, psychosexual and addiction services were also represented.

Twenty-five per cent of respondents work parttime or in a job-share arrangement, ranging from five to eight sessions. Of the remainder, one works 13 sessions, and the rest 10 , per week. Only one staff psychiatrist was contracted to participate regularly in an on call rota ('one in 6'; 'first on call'). Two other respondents did occasional 'first on call' as service demanded. The majority do no 'on call' at all!

Thirteen respondents prefer the title 'Staff psychiatrist', while 11 accept the name 'Staff grade psychiatrist'. One preferred the title 'Psychiatrist' alone.

\section{Professional relationships}

Eighty-eight per cent of respondents receive supervision of clinical work from a consultant, mostly either by a regular arrangement, or freely available as required. A third also receive supervision for research, audit and/or psychotherapeutic work.

Most respondents in turn supervise other clinical staff, mainly SHOs and non-medical members of multi-disciplinary teams.

In response to the question Which group of medical colleagues do you regard as your peers?'.
$50 \%$ replied 'consultants/associate specialists'. Other replies, in decreasing order of occurrence, were 'registrars', 'senior registrars', and 'SHOs'. Two could not position themselves on the 'training hierarchy' (one commenting that she was 'neither fish nor fowl'!). Respondents tended to identify peers of the same or higher grade than they themselves had previously occupied.

Mixed responses were also given to the question 'How is the staff grade perceived by your medical and non-medical colleagues?'. Half felt entirely positively regarded, and some offered reasons such as providing good clinical service or being approachable by colleagues. Only one felt entirely negatively, and unjustifiably, regarded as 'just a junior'. The remainder described mixed perceptions, mainly focused on difficulty being placed on the training hierarchy, and misunderstanding of their career path.

\section{Content of job}

Despite only one respondent being on a contractual 'on call' rota, almost all conduct emergency assessments of patients. Similarly, out-patient clinics and domiciliary assessments/treatment were routine aspects of most staff psychiatrists' workload. The majority also perform regular liaison and psychiatric in-patient work. A minority are involved in administration/supervision of electroconvulsive therapy, or day hospital assessments and reviews. Several do specialised clinics, including clozapine supervision, alcohol dependence and psychosexual medicine.

Most respondents have administrative/managerial duties, mainly organising clinical activities, and a variety of committee work. The majority have teaching commitments, especially to medical students, but also to non-medical students/staff.

Few respondents indicated any changes they would wish to make to the content of their job. The only suggestions made involved increased variety of experience, such as more managerial or teaching responsibilities, or exposure to specialist clinics.

\section{Education}

All respondents are regularly involved in educational activities, mainly local case conferences/ presentations. Half of the sample, and in particular those intending to sit MRCPsych examinations, also participate in journal clubs or attend academic meetings and formal teaching sessions. Two do not have access to adequate library facilities.

The percentage of respondents' current study leave entitlement (full-time equivalent per annum) is summarised: 10 days or more $60 \%$, less than 10 days $10 \%$, no formal study leave $12 \%$, 
uncertain of entitlement $18 \%$. (Under nationally agreed Terms and Conditions of Service, the recommended entitlement of paid study leave, in the UK, with reasonable expenses, is a maximum of $\mathbf{3 0}$ days, in any period of three years.)

Of those respondents entitled to regular study leave, only $60 \%$ had used it at all during the past year, taking on average, six days leave from a possible 10 (full-time equivalent).

Twenty-eight per cent of respondents are currently preparing for, or intend to sit, the MRCPsych Part II examination as a staff grade. Some of this group had already ensured that their post would be approved for training/ examination purposes.

Twenty per cent are registered with the Royal College of Psychiatrists for Continuing Professional Development (CPD). Some respondents indicated their lack of awareness about eligibility to register for CPD. Three respondents are currently doing, or intend to undertake, additional training in the psychotherapies.

Only $64 \%$ of respondents described their current post as adequately meeting their educational needs. Improvements desired included improved access to library and computer facilities; obtaining study leave entitlement (where this was absent); increased formal teaching, consultant supervision and general training opportunities; and gaining permission to sit MRCPsych examinations.

\section{Research/audit}

Only $50 \%$ of respondents are actively involved in clinical audit, $28 \%$ in medical audit, and $32 \%$ in research. Three have had one single publication as a staff grade.

\section{Career intentions}

On first qualifying as a doctor, $40 \%$ had intended to become a consultant psychiatrist, $24 \%$ a GP. $12 \%$ a consultant in a speciality other than psychiatry. Eight per cent had planned a career outside medicine, and $4 \%$ in academic medicine. Twelve per cent had been uncertain. Current intentions were: $44 \%$ to progress to associate specialist, $24 \%$ to consultant psychiatrist and $4 \%$ to GP. Only $20 \%$ intended to remain in the staff grade, and $4 \%$ were uncertain.

Of those who hoped to progress to consultant or associate specialist status, $60 \%$ believed they had a good chance of doing so.

\section{Overall view}

Ninety-six per cent of respondents regarded the staff grade as useful, and offered several reasons why. It was regarded as useful to the service by filling gaps in service, relieving consultants of clinical duties, improving continuing care of chronically disabled patients, and providing inexpensive medical cover. It was also described as useful to the staff grade psychiatrists themselves, by offering an opportunity to develop clinical experience, and research/specialist interest; and to practise responsibility at an intermediate grade. Flexibility, security, stability and good hours and general working conditions were also noted. Many regarded the grade as a break from formal training, and others as a route into psychiatry from another field. General job satisfaction and enhanced quality of life were commonly reported. Overall, $44 \%$ of respondents described themselves as very satisfied', and $44 \%$ as 'reasonably satisfied' in their current post. Dissatisfaction due to low pay, poor status, absence of career prospects and inadequate support/supervision was described by a minority.

\section{Comment}

It may be concluded that staff grade psychiatry posts within Scotland have attracted doctors from a variety of professional and personal backgrounds for various and, generally, positive reasons. On the whole, Scottish staff psychiatrists remain happy in their position, although longer-term career intentions differ widely. It is noteworthy that only $20 \%$ of respondents wish to remain in the grade. For only a minority, therefore, is their current post regarded as a job for life'. In this, and certain other respects, Scottish staff grade psychiatrists differ from what may have been intended by Manpower planners (DHSS, 1986). They are a heterogeneous group of doctors, some highly qualified, and generally from more senior prior posts. The SCOPME (1994) and SCPMDE (1996) reports made similar findings.

However, Scottish staff grade psychiatrists do differ from their counterparts in other specialities and areas of Britain in some respects. Notably, the large groups of overseas-qualified men found in the SCOPME and SCPMDE samples (59.5 and 33\%, respectively) were not a feature of this study. In addition, reasons for opting for the grade were similar in type, but differed in rank order, between the three studies. The primary attraction of regular 'office hours' within Scottish staff grade psychiatry posts may simply reflect their more favourable working conditions compared with other specialities. For example, only one of my respondents had contractual, routine on-call duties, while the SCPMDE report identified $48 \%$ of staff grade doctors and dentists as doing regular out of hours on-call duties, often on rotas along with $\mathrm{SHO} /$ registrar or senior registrar grades, and $30 \%$ of the SCOPME sample also had on-call commitments. Psychiatrists also fared better 
than their colleagues in other specialities within Scotland in terms of receiving helpful career advice, as recommended in the DHSS Report (1986). Half of the sample had been satisfactorily advised prior to applying for their staff grade post, compared with $31 \%$ of the SCPMDE sample.

It should be questioned why so many psychiatrists have been attracted out of registrar posts into the staff grade. Perhaps we are seeing the legacy of the intolerable resident on call conditions which marked training in the 1980s. It is also possible that many have sought temporary refuge in this intermediate career grade from the rigidity and pace of the linear training system. It is noteworthy that respondents commonly reported that the intrinsic educational value of the post had attracted them to it. Most important, was the experience of medium/long-term contact with patients, which features rarely in training posts, yet represents a particularly interesting, if demanding, aspect of consultant work. While it may seem inappropriate to regard staff grade jobs as alternative training posts, it is clear that many psychiatrists make this 'training detour', or long-term career choice, in order to enhance their learning. There is, however, no room for complacency since in comparison with staff grades in other specialities, especially surgery and obstetrics and gynaecology, Scottish psychiatrists have fewer formal arrangements for study leave (SCOPME, 1994). Comparing this study sample with staff grade psychiatrists in England and Wales, the former fare slightly better in terms of educational opportunities, but, possibly because of geographical isolation, have less access to adequate library facilities (The SCPMDE Report similarly identified library access as a problem unique to Scottish staff grades).

Hence, in order to continue attracting highcalibre psychiatrists to staff grade posts, opportunities for continuing education and training, and for some form of career progression, must be created.

I propose that there are certain prerequisites for universal participation of staff grades in some form of CPD. First, reasonable study leave should remain part of any acceptable Terms and Conditions of Service, and provision made for uptake of such leave by staff grades (for example, arrangements for covering clinical commitments). Second, adequate library and computing facilities should be available to all practitioners, particularly those in geographically isolated posts. Third, staff grades should continue to be encouraged to form links with the College. The previous survey of staff grade psychiatrists within the South-East Thames region demonstrated unanimous support for some sort of representation at the College (Stein,
1997). This should help minimise isolation within the grade, and maximise educational opportunities through receiving College publications and invitations to meetings. The recently created affiliate status is a welcome development. However, access to College membership remains important for many staff grades. The SCOPME report noted that fewer staff grade psychiatrists had College membership compared with possession of the corresponding postgraduate qualification by their colleagues in certain other specialities. In my view, provided their posts meet necessary educational/training requirements, individual staff grades should continue to be permitted to sit College membership examinations, whatever their ultimate career intentions.

An additional, helpful step would be a clear invitation to all staff grades to participate in the College's CPD programme. Many seem unaware of their eligibility to register. Also, because of their varied prior training and experience, and differing career intentions, staff grade psychiatrists may require individualised CPD programmes. These could be developed by each staff grade along with their supervising consultant and/or clinical tutor, and submitted to their deputy regional adviser for approval. Regular reviews, annually at least, might be a useful means of monitoring clinical and educational progress. (The South-East Thames sample all wanted some sort of regular meeting with the regional advisor or his/her deputy (Stein, 1997)). The right balance between participation in specialist-level CPD, and attending training grade programmes, should be sought for each individual.

Finally, the majority of Scottish staff grade psychiatrists who wish to progress to a different grade should be offered some clear means of doing so. The present situation is rather confused, with progression to associate specialist seeming rather idiosyncratic, and few clear guidelines about re-entering training schemes. Although the specialist medical order makes no provision for formally recognising post-membership experience in the staff grade toward higher training, psychiatrists wishing to re-enter specialist training may find that their staff grade posts have so enhanced their curriculum vitae as to benefit them in open competition for training grade posts. Certainly, such active competition for posts is to be encouraged, and guidance may be sought from postgraduate deans and tutors. For the majority (at least $64 \%$ of this study sample), who do not wish to pursue higher training, a parallel non-consultant career system could be developed, with a clear structure involving its own training requirements and rewards. Previous suggestions have included 'proficiency bars' determined by a combination 
of interviews and continuing medical education 'credits' (Royal College of Physicians, 1993). Throughout, a reasonable balance should be sought between regarding the grade as mere 'marking time' and viewing it as some 'alternative' training post.

Ultimately the success of the grade will be determined by the ability of staff psychiatrists to serve their patients and colleagues well. We require skills and incentives to do both.

\section{Acknowledgements}

I thank my colleagues in the West of Scotland Staff Grade Psychiatrists' Committee for helping compile the database used in this study.

\section{References}

DEPARTMENT OF HEALTH AND SOCIAL SECURTY (1986) Hospital Medical Staffing: Achieving a Balance. London: DHSS.
- (1987) Hospital Medical Staffing: Achieving a Balance Plan for Action. London: DHSS.

Royal College of Physicians (1993) Staff Grade Doctors: Towards a Better Future. London: Royal College of Physicians.

ROYAL COLLEGE OF PSYCHIATRISTS (1995) Annual Census of Psychiatric Staffing (Occasional Paper OP34). London: Royal College of Psychiatrists.

SCOTtish COUNCIL fOR POSTGRaduate Medical and DENTA EDUCATION (1996) The educational needs of Staff Grade Doctors and Dentists in Scotland. Health Bulletin. 54. 318-331.

Standing Committee on Postgraduate Medical Education (1994) Meeting the Educational Needs of Staff Grade Doctors and Dentists. London: SCOPME.

STEIN, G. (1997) Meetings with doctors in the staff grades: the development of affiliate status. Psychiatric Bulletin. 21. 405-407.

Aileen Blower, Staff Grade Psychiatrist, Department of Child and Adolescent Psychiatry, Lomond Healthcare NHS Trust, Vale of Leven District General Hospital, Alexandria, Dunbartonshire

\title{
Sweets, newspapers and analgesics: patients' purchases from hospital shops
}

\author{
David Somerfield
}

\begin{abstract}
Aims and method The study was undertaken to examine over the counter drug sales from hospital shops. One hundred hospital shops were sent a questionnaire asking for details of drugs sold and any policy to prevent sales to patients.

Results Seventy-three shops replied, 20 of which sold medication. Most had policies which would allow sales to patients. Three shops had sold medication which was subsequently used for self-poisoning by in-patients.

Clinical implications Hospital managers and clinicians should ensure hospital shops have effective policies to prevent medication sales to patients.
\end{abstract}

Hospital shops provide an invaluable service to patients, relatives and staff. Some shops may stock drugs which are not classified as prescrip- tion only medicines and can be sold over the counter. They may sell the generic preparations of paracetamol, aspirin or ibuprofen or proprietary compound preparations containing these drugs and a variety of other substances. These are safe and well tolerated analgesics and anti-pyretics when taken at recommended dosage but in deliberate or non-deliberate overdose can create considerable morbidity and are potentially fatal. Hospitals concentrate a disproportionately high number of patients at risk of deliberate self-harm and suicide. Despite preventative measures inpatients still harm themselves. Jacobson et al (1986) showed the rate of deliberate self-harm for all psychiatric admissions over a nine-year period was $6.2 \%$. Self-mutilation was the most common method, with overdose representing over 